\title{
Solar Activity and Climate Change Hazards
}

\author{
Ahmed A. Hady \\ Department of Astronomy \& Space and Meteorology, Faculty of Sciences, Cairo University, Giza 12613, Egypt
}

\begin{abstract}
This paper discusses that the global worming caused by the green-house gases effect will be equal or less than that of the global cooling resulting from the solar activities. In this respect, we refer to the MDM (Modern Dalton Minimum) which stated that starting from 2005 to the next 40 years; the earth's surface temperature will become cooler than nowadays. However, the degree of cooling, previously mentioned in old Dalton Minimum (c. 210 year ago), will be minimized by building-up of green-house gases effect during MDM period. Regarding to the periodicities of solar activities, it is clear that we have a new solar cycle of around 210 years now.
\end{abstract}

Key words: Solar activities, solar cycles, palaeoclimatic changes, global cooling, Modern Dalton Minimum.

\section{Introduction}

Throughout the geological history of the earth, climate change is one of the recurrent natural hazards. In recent history, the impact of human brought about additional climatic change. Solar activities have had notable effect on palaeoclimatic changes. Contemporarily, both solar activities and building-up of green-house gases effect are added to the climatic changes.

Nowadays, the global climatic change is an insistent phenomenon. It is affected by cosmological aspects, as well as social behavior. In this review, we consider the effect of solar activities on climate change. According to many scientists, the solar-terrestrial relations have shown profound effect on our planet, we are trying to point out the evidences that prove such relations since they rughly affect the future human's life.

The occurrence of the solar cycles is a magnetic phenomenon, related to the dynamo effect, which generates the magnetic field of the sun [1]. It is well known that solar activity exhibits an 11-year periodicity, and the more dramatic activities usually occur in the maximum of the cycle.

The 11-year solar cycle is important because it

Corresponding author: Ahmed A. Hady, professor, research field: solar physics \& space physics. E-mail: aahady@sci.cu.edu.eg. determines the long term variation of characteristics such as the earth's ionosphere, a layer of charged particles between 100 and $600 \mathrm{~km}$ above the surface of the earth. This layer is important because of its effect on radio signals, either reflecting high frequency signals or retarding those above this frequency range. The solar cycle also underpins the occurrence of short term disturbances to the earth-sun region. These arise in association with spectacular events on the sun such as solar flares, coronal mass ejections and propagate to the earth as changes in the solar wind. Disturbances disrupt the ionosphere causing rapid variations in its properties and are most obviously seen in the rapid variations in the magnetic field of the earth, events that are known as "geomagnetic storms".

The energetic solar events, which are associated with the peak and decline phase of the solar cycles, can affect the earth's atmosphere, space environments, earth's climate changes, satellites, and humankind activities. Recently, observations revealed that the SEPs (solar energetic particles) and CMEs (coronal mass ejections) with different origins were based on magnetic changes of the active region which produced the SEPs, and on the abundances, ionization states and time production of the particles as well as the longitude distribution associations of the events [2,3]. These events (SEPs and CMEs) lead to severe effects on the 
earth, such as climate change, power blackouts, disruption of communications and damage of satellites.

The complicated dynamics of magnetic fields plays a key role in the solar activities [4]. The peak of the solar cycle 21 was in 1979 but high energetic solar flares, or secondary peaks, occurred at the declining phase in 1981, 1982 and 1984 before the solar activity minimum in 1986. Also, the peak of the solar cycle 22 was in 1989 but high energetic solar flares occurred at the declining phase in 1991, 1992 and 1994, before the solar activity minimum in 1996 . Then the secondary peaks occurred during two to three years after the first peak, as deduced from the last five solar cycles [5, 6]. If a CME hit the earth, it can excite a geomagnetic storm. Large geomagnetic storms, among other things, can damage satellite communications. In space, CME typically drives shock waves that produce energetic particles that can damage both electronic equipment and astronauts. So, the predictions of the high energetic particle events are of vital importance for space navigation and airline safety [7].

The objective of this paper is to estimate the future dramatic change in the solar activities according to the past changes, and our statistical analysis.

\section{The Correlation between Climate Change and Solar Activities in History}

There is periodical change of climate through time since the Precambrian Era till now. Fig. 1 shows how global climate has changed through time. After the studies and measurements of solar activities variability during the last two centuries, the correlation between climate changes and the change in the solar irradiance were confirmed.

The depletion (permille) of $\mathrm{C}^{14}$ is a good indication of the climate change. As shown in Fig. 2, there is a good correlation between $\delta \mathrm{C}^{14}$ and the sunspot number variations.

Fig. 2 Exhibits the most obvious events that happened on solar activities through the last 400 years, and the response on the earth's climate change. These events are the Maunder Minimum, the Dalton Minimum and Modern Maximum.

The Maunder Minimum is the first obvious event in which the sunspot number was almost vanishing. This event was in the period from 1645 to 1715 . It corresponds on the earth when it was meeting the Little

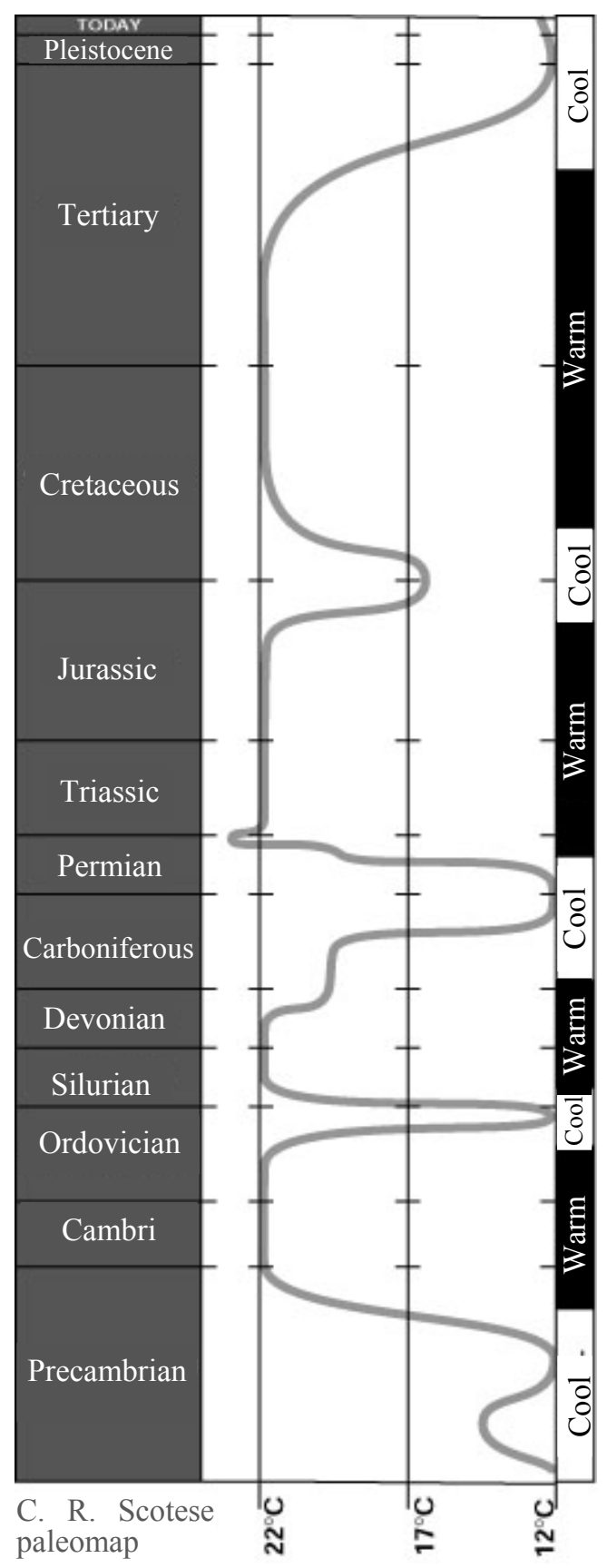

Average global temperature

Fig. 1 Global climate change through time since the Precambrian Era and till now (from the Paleomap Project, 2008, http://www.scotese.com/climate.htm). 


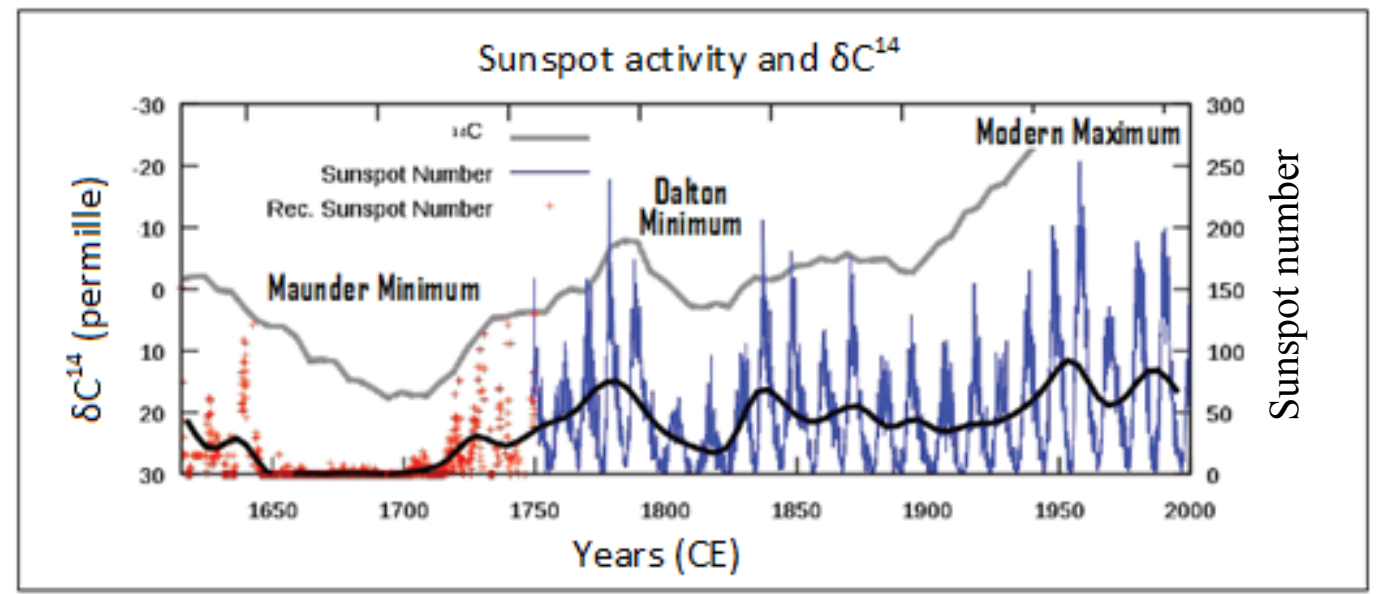

Fig. 2 The averages of annual group and Wolf sunspot number from 1600 until 2000 , and $\delta C^{14}$, where the sunspot activity in $y$-axis in the right, $\delta C^{14}$ in y-axis in left of the figure (from NOAA's Space Environment Center, http://www.swpc.noaa.gov).

Ice Age, which was obviously recorded from 1650 to 1720. This Little Ice Age brought bitterly cold winters to many parts of the world, but it was most documented in Europe and North America. In the mid-17th century, glaciers in the Swiss Alps showed to expand. The River Thames and the canals and rivers of the Netherlands often froze during the winter. The coincidence of the Maunder Minimum with the deepest trough of the Little Ice Age is suggestive of such connection.

The Dalton Minimum is a period of low solar activity (Fig. 2). It lasted from about 1790 to 1830. It also paralleled with a period of global temperature lower than average. It was recorded that the average temperature in the American Mid-west was $2^{\circ}-4^{\circ}$ cooler than that of the 20th century average, in many areas. It was much dryer than average, especially along the California coast.

The Modern Maximum is a period of relatively high solar activity that began in 1950. The earth's temperature from 1950 till 1990 was obvious to be increasing which correlated with the Modern Maximum period of the sun that has corresponds to a relative large number of sunspots indicating active solar activity.

Solar activity is thus indicative of the climate changes through time in history. For more details see Refs. [8-11].

\section{The Modern Dalton Minimum and 210 Years Solar Cycle}

The long term periodicity of sunspot number can be classified as follows:

(1) 11-year cycle: known as Schwabe cycle, sometimes called the "main solar cycle", and this happens due to the shedding of entangled magnetic fields;

(2) 22-year cycle: the magnetic field of the sun is reversed during each Schwabe cycle, thus the magnetic poles are returned to the same state after two reversals;

(3) 87-year cycle (70-100 years): known as Wolf-Gliessberg cycle, is thought to be an amplitude modulation of the 11-year Schwabe cycle. Wolf-Gleissberg observed 17 cycles from the year 290 $\mathrm{AD}$ (with mean duration of 78 years). The length of the cycle is not constant; varying quite considerably (approximately $85 \pm 15$ years). The last maxima of Wolf-Gleissberg cycle appeared approximately in periods: (1710-1720), (1760-1770), (1840-1850) and (1950-1960). The last minima of Wolf-Gleissberg cycle then fit approximately to the years: 1740,1810 , 1900, and 1990, as shown in Fig. 3. The maximum duration (1760-1770) of Wolf-Gleissberg is not fit with the period of 87-year cycle.

The occurrence of climate changes at the turning points of Wolf-Gleissberg cycles is shown in Fig. 3. 
There is an indication that occurrence of the maximum turning point of Wolf-Gleissberg cycles (1957-1959), corresponding to solar cycle 19 , which associated with a worm climate (modern maximum), and followed by the weak cycle number 20 .

A weak cycle number 23, started in 1996, is the first weak cycle of a series of very weak solar cycles, and the indication of cool climate change, for more details see Refs. [12, 13].

Starting from solar cycles 23 and 24, a weak solar activity period was started associated with global cooling period. If the cycles 25,26 are also weak cycles (according our predictions, like cycle 24), then palter of Dalton Minimum may repeat leading to a new cycle of 210 years. In this case, the Wolf-Gleissberg cycles will be invalidated.

In addition, solar cycle 24 which started in 2008, its maximum during 2012-2014 behaves as a very poor cycle, its behavior like the solar cycle 5, during Dalton Minimum.

Time series of sunspot number, illustrating the existence of weak solar cycle's series around the $1700 \mathrm{~s}$, $1800 \mathrm{~s}, 1900 \mathrm{~s}$ and 2000s were shown in Fig. 4. The prediction of cycles 24-26 is given at the extreme right of the figure as a repetition of cycles 5-7 around $1800 \mathrm{~s}$, during Dalton Minimum.

Fig. 5 shows the solar cycles 3-6 during Dalton Minimum era overwhelm on the new solar cycles 23-24, until July 2014. This repetition of the cycle's intensity gets induction of the future cycles 25 and 26 .

We stated that, there is a new Dalton Minimum, so-called MDM (Modern Dalton Minimum) stared in 2005 and extended for about 40 years, in such case, the earth's surface global temperature will be cooler, and a short term climatic change will happen.

We note that the solar cycle 24 has two peaks as shown in Fig. 5, as for the cycles 20-23. This is the only difference between Dalton Minimum cycles 4-7 and Modern Dalton Minimum cycles 23-26.

This gives the impression of the existence of a new global cooling in that period, such as given during Dalton Minimum Era; this period can be called MDM.

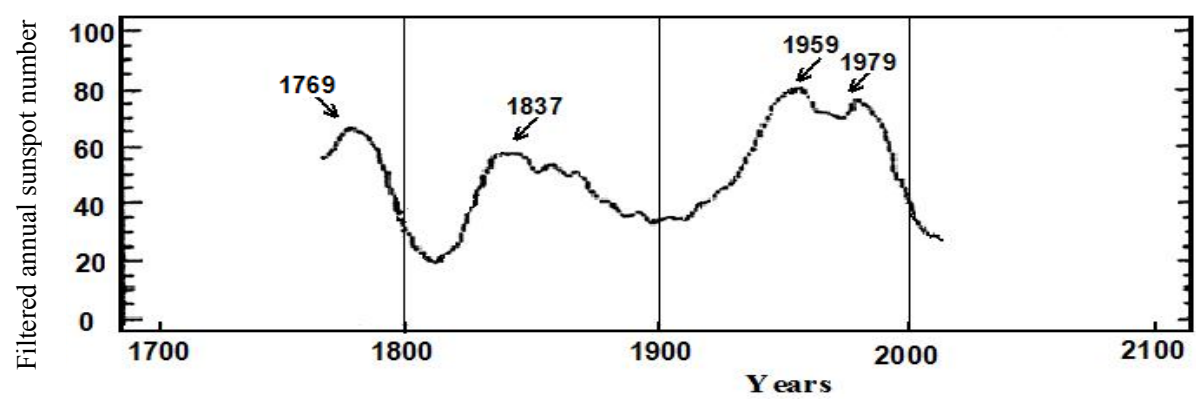

Fig. 3 Wolf-Gleissberg cycles for the period (1770-2010).

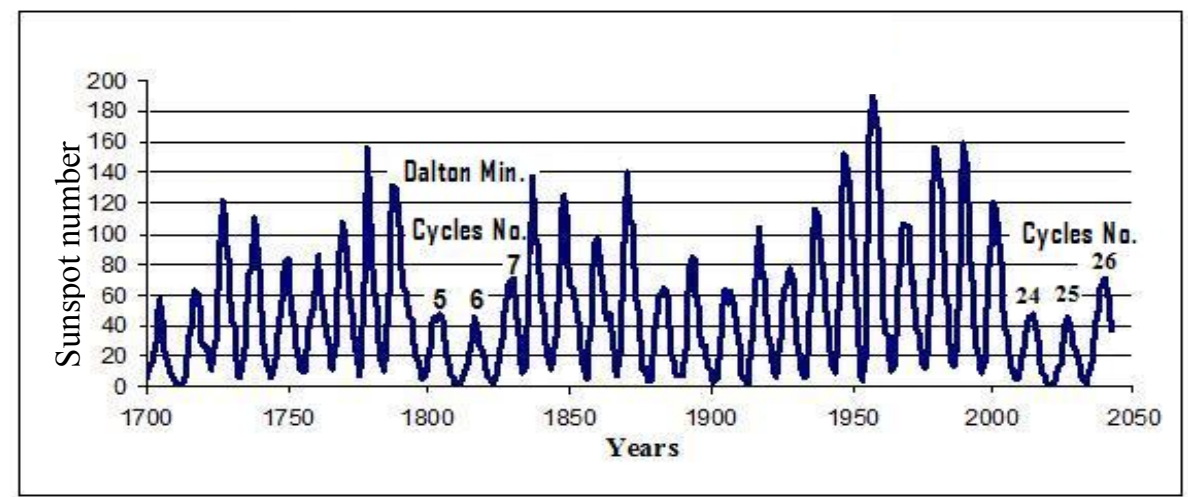

Fig. 4 The solar cycles from 1700 to 2040. The prediction of solar cycles 25 and 26 were shown in the figure (source of diagram: http://www.universetoday.com/103803/solar-cycle-24-on-track-to-be-the-weakest-in-100-years). 


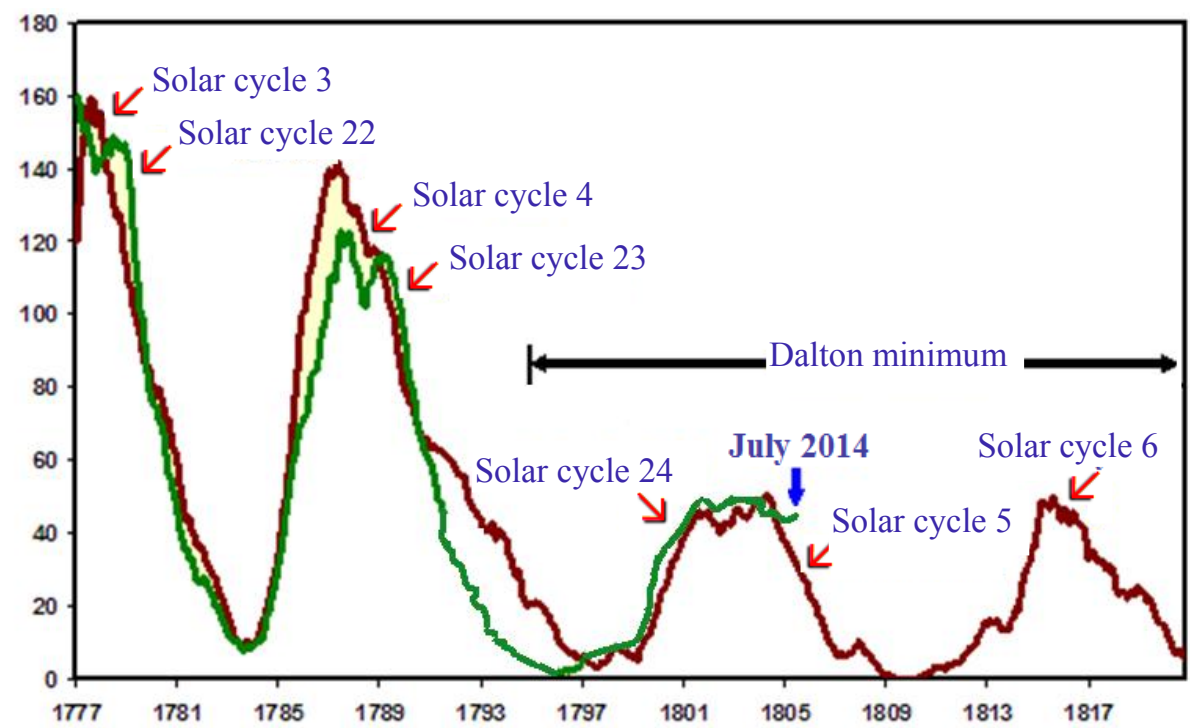

Fig. 5 Dalton Minimum Era and the solar cycles 22-24 are overlaid on solar cycles 3-5 above to show similarity, the date given until July 2014.

Nowadays, After the extensive solar observation by ground and space base, the existences of the new solar cycle with longer period is evident.

In Fig. 5, the cycle of 210 years is the best fitting with the observations than the Wolf-Gleissberg cycles.

Based on the periodicities of solar activities, the authors are encouraged to state that a new solar cycle of around 210 years.

The authors note that the period around 210 years can be new solar cycle is logic. They can notes that the cycles from cycle-1 to cycle-7 are repetitions of solar cycles from cycle-20 to cycle-26.

This means that the time period of 19 cycles is the lag time for repetition, which covered about 210 years.

\section{Solar Cycles and the Green-House Gases Effect}

A comparison between the statistical results of all solar cycles in history, and the predictions of solar cycle 24 are given in Table 1, see Ref. [14]. The prediction of cycle 24 as given in Table 1, will be published later in another paper.

From Table 1 and Fig. 4, we can conclude that the solar activity rapidly declined starting from the year 2005 and will continue for the next 40 years. The earth's surface global cooling in time of low solar activity is on average $\left(-0.2^{\circ} \mathrm{C}\right.$ during 40 years $)$ cooler than times of higher solar activity. Prevalent global warming is on average $\left(+0.15^{\circ} \mathrm{C}\right)$ during last 50 years, caused by building-up of green-house gases in the troposphere, and seems to be close to the current cooling solar effects.

Fig. 6 compares the changes during last 150 years for solar cycle variations, earth surface temperature, and $\mathrm{CO}_{2}$ variability. We notice that agreement for the parameters variation occurred.

There is no enough cooling during the MDM between solar cycle variations and earth surface temperature after the $\mathrm{CO}_{2}$ dramatic increase since 1960.

The scientific consensus is that solar variations do not seem to play a major role in determining present-day observed climate change, but have played a major role in palaeoclimatic changes. For example, the dramatic climate cooling during the Maunder Minimum (1645-1710), and Dalton Minimum (1797-1825) was attributed to the solar activities collapse.

Then the solar activities have had notable effect on palaeoclimatic changes. Contemporarily, both solar activities and building-up of green-house gases effect added to the climatic changes. The global worming 
Table 1 Minimum and maximum of sunspot in the series of solar cycles.

\begin{tabular}{|c|c|c|c|c|c|c|c|}
\hline $\begin{array}{l}\text { Sunspot cycle } \\
\text { number }\end{array}$ & Year of min & $\begin{array}{l}\text { Smallest smoothed } \\
\text { monthly mean }\end{array}$ & Year of max & $\begin{array}{l}\text { Largest smoothed } \\
\text { monthly mean }\end{array}$ & $\begin{array}{l}\text { Rise to max } \\
\text { (years) }\end{array}$ & $\begin{array}{l}\text { Fall to min } \\
\text { (years) }\end{array}$ & $\begin{array}{l}\text { Cycle length } \\
\text { (years) }\end{array}$ \\
\hline 1 & $1,755.2$ & 8.4 & $1,761.5$ & 86.5 & 6.3 & 5.0 & 11.3 \\
\hline 2 & $1,766.5$ & 11.2 & $1,769.7$ & 115.8 & 3.2 & 5.8 & 9.0 \\
\hline 3 & $1,775.5$ & 7.2 & $1,778.4$ & 158.5 & 2.9 & 6.3 & 9.2 \\
\hline 4 & $1,784.7$ & 9.5 & $1,788.1$ & 141.2 & 3.4 & 10.2 & 13.6 \\
\hline 5 & $1,798.3$ & 3.2 & $1,805.2$ & 49.2 & 6.9 & 5.4 & 12.3 \\
\hline 6 & $1,810.6$ & 0.0 & $1,816.4$ & 48.7 & 5.8 & 6.9 & 12.7 \\
\hline 7 & $1,823.3$ & 0.1 & $1,829.9$ & 71.7 & 6.6 & 4.0 & 10.6 \\
\hline 8 & $1,833.9$ & 7.3 & $1,837.2$ & 146.9 & 3.3 & 6.3 & 9.6 \\
\hline 9 & $1,843.5$ & 10.5 & $1,848.1$ & 131.6 & 4.6 & 7.9 & 12.5 \\
\hline 10 & $1,856.0$ & 3.2 & $1,860.1$ & 97.9 & 4.1 & 7.1 & 11.2 \\
\hline 11 & $1,867.2$ & 5.2 & $1,870.6$ & 140.5 & 3.4 & 8.3 & 11.7 \\
\hline 12 & $1,878.9$ & 2.2 & $1,883.9$ & 74.6 & 5.0 & 5.7 & 10.7 \\
\hline 13 & $1,889.6$ & 5.0 & $1,894.1$ & 87.9 & 4.5 & 7.6 & 12.1 \\
\hline 14 & $1,901.7$ & 2.6 & $1,907.0$ & 64.2 & 5.3 & 6.6 & 11.9 \\
\hline 15 & $1,913.6$ & 1.5 & $1,917.6$ & 105.4 & 4.0 & 6.0 & 10.0 \\
\hline 16 & $1,923.6$ & 5.6 & $1,928.4$ & 78.1 & 4.8 & 5.4 & 10.2 \\
\hline 17 & $1,933.8$ & 3.4 & $1,937.4$ & 119.2 & 3.6 & 6.8 & 10.4 \\
\hline 18 & $1,844.2$ & 7.7 & $1,947.5$ & 151.8 & 3.3 & 6.8 & 10.1 \\
\hline 19 & $1,954.3$ & 3.4 & $1,957.9$ & 201.3 & 3.6 & 7.0 & 10.6 \\
\hline 20 & $1,964.9$ & 9.6 & $1,968.9$ & 110.6 & 4.0 & 7.6 & 11.6 \\
\hline 21 & $1,976.5$ & 12.2 & $1,979.9$ & 164.5 & 3.4 & 6.9 & 10.3 \\
\hline 22 & $1,986.8$ & 12.3 & $1,989.6$ & 158.5 & 2.8 & 6.8 & 9.7 \\
\hline 23 & $1,996.4$ & 8.0 & $2,000.3$ & 120.8 & 3.5 & 9.5 & 13.0 \\
\hline \multirow{2}{*}{24} & \multicolumn{7}{|c|}{ Author's prediction of cycle 24} \\
\hline & 2008.1 & 2.0 & $2012-2014$ & 47.0 & 5.0 & 8.5 & 13.5 \\
\hline \multicolumn{2}{|c|}{ Mean cycle values: } & 5.9 & - & 111.4 & 4.3 & 6.8 & 11.07 \\
\hline
\end{tabular}

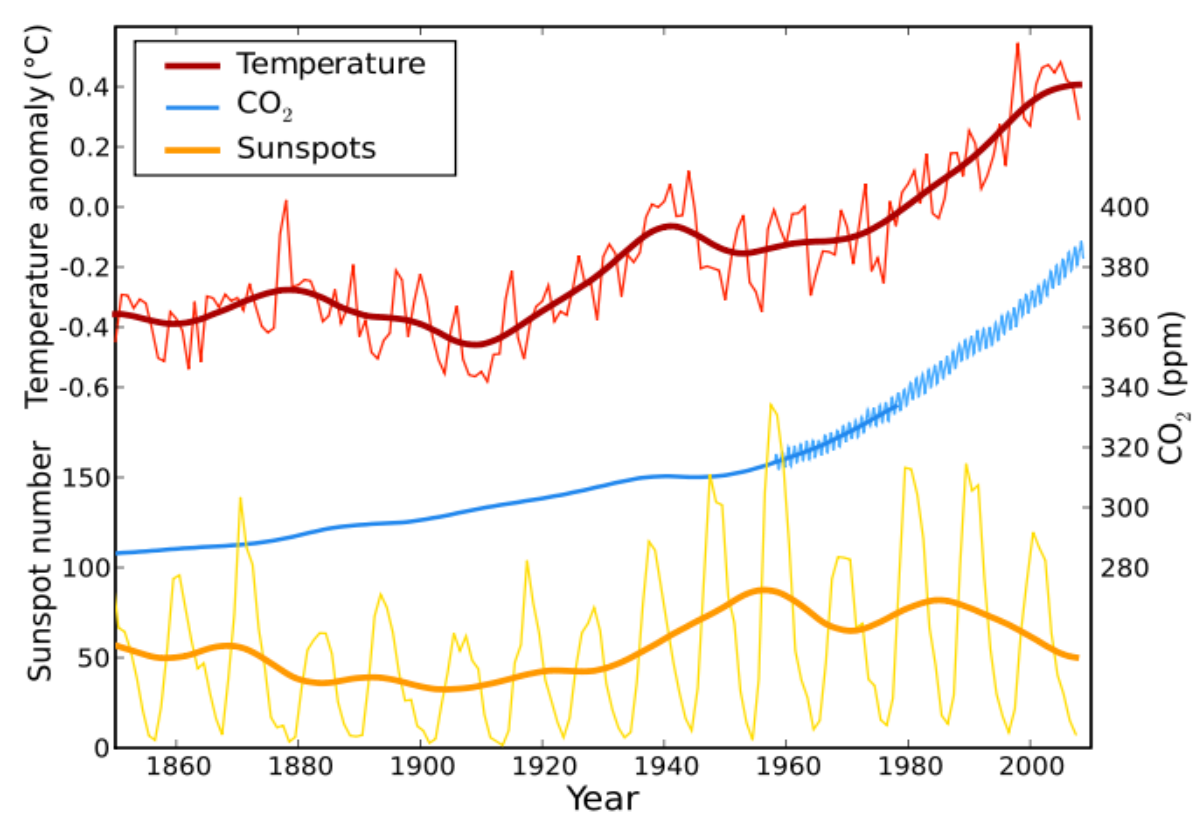

Fig. 6 Temperature, $\mathrm{CO}_{2}$ concentration in the troposphere, and sunspots variations starting from 1850 to 2010 [14]. 
caused by the green-house gases effect little less than that of the global cooling resulting from the solar activities.

\section{Conclusions}

From this review paper, we can conclude as follow:

There is a new Dalton Minimum, so-called MDM stated year from 2005 for about 40 years.

The existences of the new solar cycle with longer period (c. 210 year) appear as a new solar cycle. The time period of 19 cycles is the lag time for repetition, which covered about 210 years.

Solar activities have had notable effect on palaeoclimatic changes. Contemporarily, both solar activities and building-up of green-house gases effect are added to the climatic changes. The green-house gases effect will be little less than the global cooling resulting from the solar activities during MDM.

\section{Acknowledgements}

The author is indebted to professor Mosalam Shaltout, NRIAG (National Institute of Astronomy and Geophysics), Egypt for the proof reading of the manuscript.

\section{References}

[1] Zeldovich, Ya. B., Ruzmaikin, A. A., and Sokoloff, D. D. 1983. Magnetic Field in Astrophysics. New York: Golden and Breach Sciences Publishers.

[2] Reames, D. V., Meyer, J. P., and Von Rosenvinge, T. T. 1994. "Energetic-Particle Abundance in Impulsive Solar Flare Events." Astrophysical Journal Supplement Series
90 (February): 649-67.

[3] Reames, D. V. 1995. "Solar Energetic Particles: A Paradigm Shift.” Revs. Geophys. (Suppl.) 33 (July): 585-9.

[4] Parker, E. N. 2001. "Solar Activity and Classical Physics" Chinese Journal of Astronomy and Astrophysics 1 (2): 99. doi:10.1088/1009-9271/1/2/99.

[5] Shaltout, M. 1995. "High Energetic Solar Proton Flares on the Declining Phase of Solar Cycle 22." Astrophysics and Space Science 228 (1-2): 67-75.

[6] Shaltout, M. S., and Hady, A. A. 2001. "Correlation between Solar Proton Flares near the 23rd Solar Maximum and the Radiation Hazard at Aircraft Altitude." In Proceedings of the IAGA-IASPEI, Joint Scientific Assembly, 19-31.

[7] Hady, A. 2002. "Analytical Studies of Solar Cycle 23 and Its Periodicities" Planetary and Space Science 50 (1): 89-92.

[8] Hathaway, D. H. 2010. "Does the Current Minimum Validate (or Invalidate) Cycle Prediction Methods?" In Proceedings of the SOHO-23: Understanding a Peculiar Solar Minimum, 307-14.

[9] Hathaway, D. H. 2010. "The Solar Cycle." Living Rev. Solar Phys. 7: 1-65.

[10] Solanki, S. K. 2002. "Solar Variability and Climate Change: Is There a Link?" Astronomy \& Geophysics 43 (5): 509-13.

[11] Yousef, S. M. 2000. "The Solar Wolf-Gleissberg Cycle and Its Influence on the Earth." In Proceedings of the ICEHM2000, 267-93.

[12] Hady, A. A. 2013. "Deep Solar Minimum and Global Climate Changes." Journal of Advance Research 4 (3): 209-14.

[13] Hady, A. A. 2013. "Solar Activities and Space Weather Hazards." In Proceedings of the 4th International Conference on MTPR-10, 30-5.

[14] Hady, A. A. 2011. "Climate Change: Global, Regional and National Dimensions." In Proceedings of the NATO Advanced Research Workshop on Global Climate Change and Local Adaptation, 547-60. 